\title{
Study of Airborne Transmission of Covid-19 In Different Climatic Conditions
}

\author{
Sonali Majumdar ${ }^{1}$, Narayan D. Totewad*2 \\ ${ }^{1}$ School of Chemical Sciences, Devi Ahilya Vishwavidyalaya, Indore, Madhya Pradesh, India \\ ${ }^{*}$ B. K. Birla College of Arts, Science and Commerce (Autonomous), Kalyan, Maharashtra, India
}

Article Info

Volume 8 Issue 2

Page Number: 116-120

\section{Publication Issue :}

March-April-2021

\section{Article History}

Accepted : 23 March 2021

Published : 28 March 2021

\section{ABSTRACT}

COVID-19 is a contagious disease caused by a newly discovered virus, SARS$\mathrm{CoV}-2$. It is known to spread through respiratory droplets and contact surfaces contaminated due to deposition of infected droplets. Recently, researchers have also found evidence of airborne transmission of Covid-19. Airborne transmission takes place through formation of aerosols which remain suspended in air for longer periods of time. This transmission heavily depends on the type of surrounding physical environment. Climatic conditions like temperature, humidity, precipitation, wind velocity, air quality, etc. might impact the transmission rate of SARS-CoV-2. In this study, we examined the relationship between some of the climatic variables and daily reported cases of Covid-19. Currently, the countries with the leading number of Covid-19 cases are the USA, Brazil, India and Russia. We studied the top most affected region from each country, namely Los Angeles, São Paulo, Mumbai and Moscow, respectively. The daily number of Covid-19 cases was correlated with three climate variables individually i.e. daily average temperature, daily average humidity, and daily average wind speed. There was a significant relationship between the variables in Sao Paulo. Overall, average wind speed was found to have the most number of statistical significant correlations with daily Covid-19 cases among all the regions.

Keywords : Covid-19, SARS-Cov-2, Respiratory, Airborne, Temperature, Humidity, Wind

\section{INTRODUCTION}

The end of this decade began with an ominous phenomenon which couldn't have been precedented. Our fast pacing world was forced to a sudden halt by a virus so miniscule, that it is invisible to our naked eyes. Midway into this year, every human being is now a witness to the devastation caused by SARSCoV-2, popularly known as novel coronavirus. The disease caused by the novel coronavirus, COVID-19, was declared a pandemic by the WHO on 11 March 2020. Around 23 million people have been infected and 799,000 people have died till 22 August 2020, worldwide, due to this pandemic. 
There have been recent studies that lead to evidence of a possible route of SARS-CoV-2 virus transmission other than droplets and fomites, i.e. airborne (via aerosols) [1],[4],[5] . This virus can be released by an infected person through sneezing, coughing or potentially even talking, in the form of droplets [2],[3]. These virion-laden droplets then deposit on various objects and may even become airborne for a period of time. A person in close proximity can be infected through inhalation. Thus the characteristics of the surrounding environment can affect the stability and viability of the airborne-droplets.

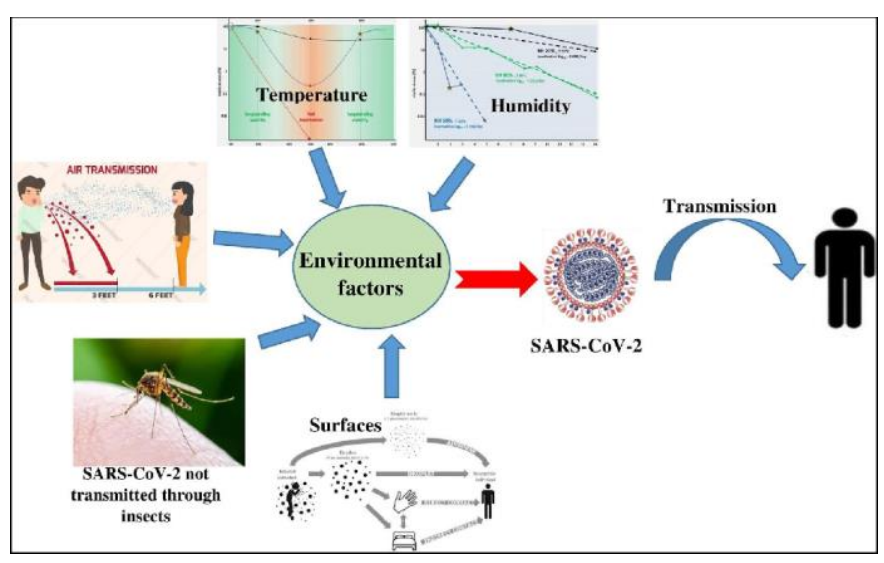

Fig 1 : Environmental factors and transmission of

$$
\text { SARS-CoV-2.[3] }
$$

The Covid-19 virus can get adsorbed on fine dust particles and particulate matter(PM), which could contribute to long-range transport of the virus [6]. Inhalation of such particles can lead to severe respiratory damage [7].Viruses such as SARS and MERS are known to have higher stability in cold environments [8],[9]. It has been suggested that the Covid-19 virus also has an optimum thriving temperature range, thus making its transmission stronger in colder climatic regions [10]. High humidity favours removal of infectious particles by allowing it to settle down and not remain suspended in air for longer durations [11]. Higher wind velocity also facilitates dilution and removal of virion-laden droplets and shortening their suspension time in air [11].

This study is thus an attempt to find the correlation between such climatic variables and transmission of SARS-CoV-2 in the four most Covid-19 affected regions of the world, i.e. Los Angeles (USA), São Paulo (Brazil), Mumbai (India) and Moscow (Russia).

\section{OBJECTIVES}

- To collect the daily Covid-19 dataset of the four most affected regions globally.

- To retrieve daily weather data i.e. average temperature $\left({ }^{\circ} \mathrm{F}\right)$, average humidity (\%) and average wind speed (mph) for each region.

- To run a correlation test on daily Covid-19 data with each of the climate variables.

- To find the presence of statistical significance between the number of daily reported Covid19 cases and climatic parameters.

\section{METHODS AND MATERIAL}

\section{DATA COLLECTION}

Covid-19 Dataset: According to the statistics, the top most countries with the highest number of Covid-19 cases till date are USA, Brazil, India and Moscow, in this particular order [12]. The values of new confirmed cases reported everyday for the four highly affected regions globally

i.e. Los Angeles,USA; São Paulo, Brazil; Mumbai, India; Moscow, Russia were retrieved from their respective health departments-Los Angeleshttp://dashboard.publichealth.lacounty.gov/covid19_s urveillance_dashboard/ [13] Sao Paulohttps://covid.saude.gov.br/ [14] 
Mumbai- https://stopcoronavirus.mcgm.gov.in/ [15]

Moscow-https://xn--80aesfpebagmfblc0a.xn-p1ai/\#operational-data [16]

Weather dataset: The daily average values of climate variables temperature $\left({ }^{\circ} \mathrm{F}\right)$, humidity $(\%)$ and wind speed (mph) \{miles per hour\} for each region were procured from https://www.wunderground.com/. [17], [18], [19], [20].

Both the datasets contain the data from the onset of the pandemic in that region till recent times i.e. from the month of February 2020 till August 2020.

\section{METHOD}

For each of the 4 regions, both the Covid-19 and weather dataset were arranged in a tabular form. To carry out the statistical analysis, a Spearman Rank Correlation test was used, as the data was not normally distributed. This test is a nonparametric measure of rank correlation (statistical dependence between the rankings of two variables). It assesses how well the relationship between two variables can be described using a monotonic function [22].

This method has also been adopted to measure the relationship between weather and daily Covid-19 cases in Jakarta, Indonesia [21]. Each of the climate variables (avg temp, avg humidity, avg wind speed) was considered as an independent variable and the number of daily confirmed Covid-19 cases was considered as the dependent variable. The daily number of cases were correlated with average values of each climate variable respectively, and the statistical significance was found between each pair of variables. The Spearman rank coefficient values were p-two tailed.

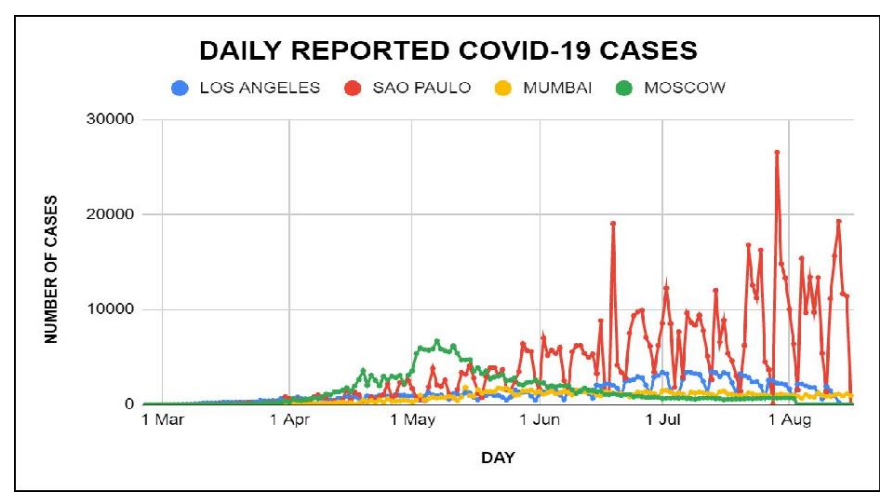

Fig 2: Number of daily reported Covid-19 cases for each region.

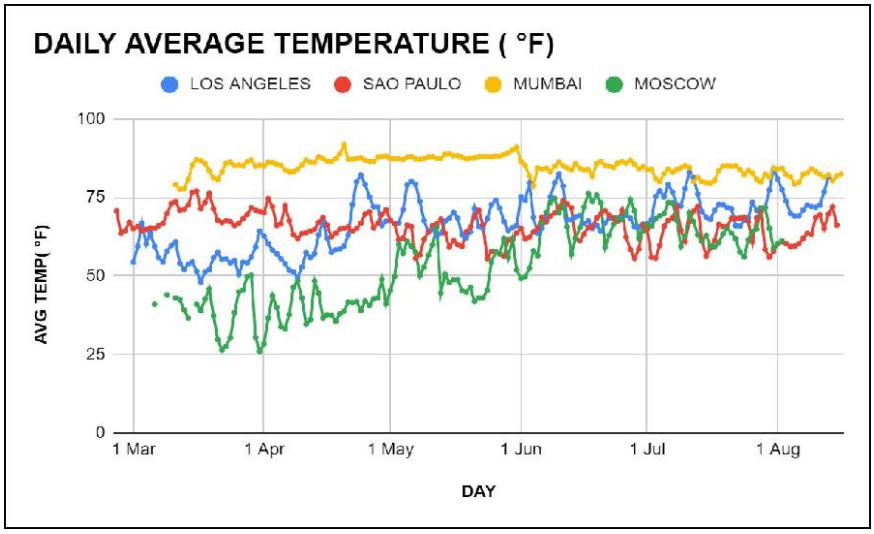

Fig 3: Daily avg temp for each region $\left({ }^{\circ} \mathrm{F}\right)$

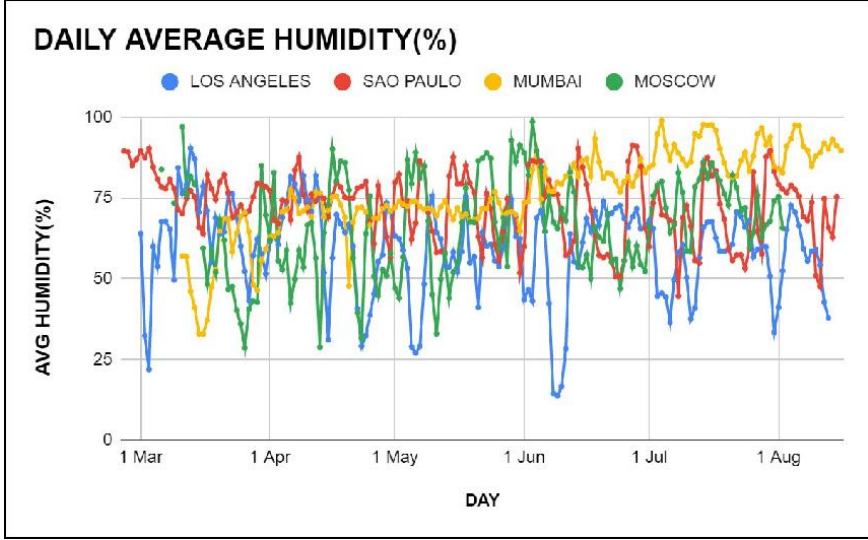

Fig 4: Daily avg humidity for each region(\%)

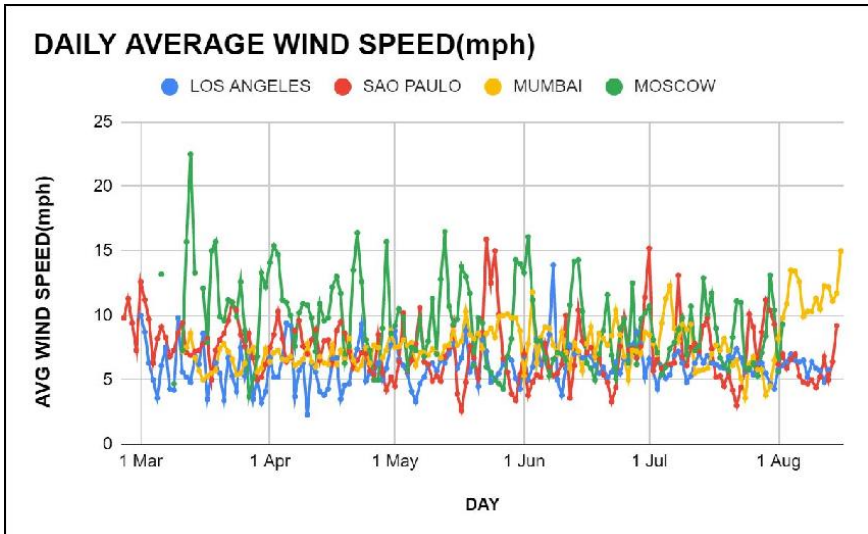

Fig 5: Daily avg wind speed(mph) for each region 


\section{RESULTS AND DISCUSSION}

From the Spearman rank correlation test, we obtained the value of Spearman rank coefficient $\left(r_{S}\right)$ and $\mathrm{p}$-value(two tailed). In significance testing, the $\mathrm{p}$ value is the probability of obtaining test results at least as extreme as the results actually observed. A pvalue of less than or equal to 0.05 is considered to be significant.

The number of daily Covid-19 cases were correlated with each of the climate variables for each region. The $r_{S}$ and $p$-values obtained are reported in a tabulated form (Table 1).

In the case of Los Angeles, the relationship between avg temp and avg wind speed was found to be statistically significant with reported daily cases and had an $r_{S}$ value of 0.60734 and 0.17366 , respectively.

This means both the factors have a positive correlation with daily Covid-19 cases.

All the climate variables had a statistically significant relation with daily cases in Sao Paulo. Each of the factors had a negative correlation with everyday positive cases.
In Mumbai, avg humidity $\left(\mathrm{r}_{\mathrm{s}}=0.52416\right.$. $)$ and avg wind speed $\left(r_{S}=0.36851\right)$ was found to have a significant correlation. Both had a positive correlation with the daily cases.

Meanwhile, in Moscow none of the climatic parameters seem to have any relation whatsoever with the number of cases.

The results indicate that there is a possibility that transmission rate of Covid-19 is affected by the climatic conditions of a particular region. The results found in this study tell us that the correlation between weather and daily cases is not consistent globally, and depends on region to region. It is difficult to predict any definite trend in weather which impacts the transmission rate, since several other epidemiological, medical and population factors were not considered in this study. This study is purely focused on an initial and preliminary investigation of any relation present between weather variables and the number of $\mathrm{nCoV}$ infected patients.

Table 1 : Statistical significance values of daily covid-19 cases vs each climate variable

\begin{tabular}{|c|c|c|c|c|c|c|}
\hline & \multicolumn{2}{|c|}{ AVG TEMP ( ${ }^{\circ}$ F) } & \multicolumn{2}{c|}{ AVG HUMIDITY(\%) } & \multicolumn{2}{c|}{$\begin{array}{c}\text { AVG WIND } \\
\text { SPEED(mph } \\
\text { ) }\end{array}$} \\
\hline & $\mathrm{r}_{\mathrm{s}}$ & p-two tailed & $\mathrm{r}_{\mathrm{s}}$ & p-two tailed & $\mathrm{r}_{\mathrm{s}}$ & $\begin{array}{c}\text { p-two } \\
\text { tailed }\end{array}$ \\
\hline $\begin{array}{c}\text { LOS } \\
\text { ANGELES }\end{array}$ & 0.60734 & 0 & -0.09516 & 0.22265 & 0.17366 & 0.02525 \\
\hline $\begin{array}{c}\text { SÃO } \\
\text { PAULO }\end{array}$ & -0.27688 & 0.00024. & -0.28368 & 0.00016 & -0.29529 & $8 \mathrm{E}-05$. \\
\hline $\begin{array}{c}\text { MUMBAI } \\
\text { MOSCOW }\end{array}$ & -0.00418 & 0.95831. & 0.52416. & 0 & 0.36851 & 0 \\
\hline MA275 & 0.32071. & 0.05174 & 0.53507. & -0.10336 & 0.21444. \\
\hline
\end{tabular}




\section{IV.CONCLUSION}

SARS-CoV-2 is a new kind of respiratory virus which has been baffling researchers all over the world due to its novel properties and characteristics, unlike the preceding viruses. This study attempts to find a relationship of transmission of this virus with respect to climatic conditions.

The relationship between the climatic variables and the transmission of Covid-19, according to the reported cases do have some statistical significance, i.e. they are correlated to each other. In 3 regions, avg wind speed is found to have a correlation with daily Covid-19 cases. But the correlation trend is not consistent across the four regions studied. This is just a preliminary stage analysis to study the presence of any relationship between the variables. In further research, other factors such as number of tests done, demographic factors, medical facilities etc must be considered for sturdier results.

The results developed from this study will be helpful in establishing an understanding of the factors which affect the propagation of $\mathrm{nCoV}$ and what measure can be taken in its mitigation. This analysis also has the perspective to act as a precursor for further research in this direction, with significant additions.

\section{ACKNOWLEDGMENT}

We are thankful to CSIR-Summer Research Training Programme (CSIR-SRTP 2020) online, coordinated by CSIR-NEIST, Jorhat, Assam for providing summer training from June to August 2020.

\section{REFERENCES}

[1]. World Health Organization, 2020. Modes of transmission of virus causing COVID-19: implications for IPC precaution recommendations: scientific brief, 27 March 2020 (No. WHO/2019-nCoV/Sci_Brief
/Transmission_modes/2020.1). World Health Organization.

[2]. Huang, H., Fan, C., Li, M., Nie, H.L., Wang, F.B., Wang, H., Wang, R., Xia, J., Zheng, X., Zuo, X. and Huang, J., 2020. COVID-19: A Call for Physical Scientists and Engineers. ACS nano, 14(4), pp.3747-3754.

[3]. Eslami, H. and Jalili, M., 2020. The role of environmental factors to transmission of SARSCoV-2 (COVID-19). AMB Express, 10(1), pp.18.

[4]. Santarpia, J.L., Rivera, D.N., Herrera, V., Morwitzer, M.J., Creager, H., Santarpia, G.W., Crown, K.K., Brett-Major, D., Schnaubelt, E., Broadhurst, M.J. and Lawler, J.V., 2020. Aerosol and Surface Transmission Potential of SARSCoV-2. medRxiv.

[5]. Li, Y., Qian, H., Hang, J., Chen, X., Hong, L., Liang, P., Li, J., Xiao, S., Wei, J., Liu, L., Kang, M., 2020. Evidence for Probable Aerosol Transmission of SARS-CoV-2 in a Poorly Ventilated Restaurant. medRxiv preprint doi. https://doi.org/10.1101/2020.04.16.20067728

\section{Cite this article as :}

Sonali Majumdar, Narayan D. Totewad, "Study of Airborne Transmission of Covid-19 In Different Climatic Conditions", International Journal of Scientific Research in Science, Engineering and Technology (IJSRSET), Online ISSN : 2394-4099, Print ISSN : 2395-1990, Volume 8 Issue 2, pp. 116-120, March-April 2021. Available at doi : https://doi.org/10.32628/IJSRSET218232 Journal URL : https://ijsrset.com/IJSRSET218232 